\title{
Makroskopik semen segar kambing bangsa Peranakan Etawa (PE), Boer dan Saanen di Balai Inseminasi Buatan Lembang
}

\author{
F. Mokoagow, E. Pudjihastuti, M.J. Hendrik, U. Paputungan* \\ Fakultas Peternakan Universitas Sam Ratulangi Manado. \\ *Korespondensi (corespondending author): umarpaputungan@unsrat.ac.id
}

\begin{abstract}
ABSTRAK
Penelitian ini bertujuan untuk mengetahui dan menguji secara makroskopik semen segar kambing bangsa Peranakan Etawa (PE), Boer, dan Saanen yang ada di BIB Lembang. Metode penelitian yang digunakan adalah metode pengamatan langsung. Data yang digunakan adalah data primer dan sekunder. Variabel yang di amati yaitu ejakulat, volume, warna, konsistensi, $\mathrm{pH}$ dan Bau Semen. Analisis data secara statistik deskriptif. Performan kualitas semen segar dari ketiga bangsa kambing dalam tiga bulan dilakukan melalui analisis varian uji t. Dari hasil penelitian diperoleh perbandingan kualitas semen segar kambing bangsa Peranakan Etawa (PE), Boer dan Saanen bulan September dan Oktober, September dan November setra November dan Oktober untuk frekuensi ejakulat adalah berbeda tidak nyata, dengan rata-rata ejakulat 2,47 mL 2,64 mL dan 2,70 mL masih dalam kondisi normal. Sedangkan volume semen kambing bangsa Peranakan Etawa (PE), Boer dan Saanen diperoleh perbandingan bulan September dan Oktober menunjukkan bahwa berbeda nyata, dan pada bulan September dan November, November dan Oktober menunjukkan tidak berbeda nyata dengan rata-rata volume 2,30 $\mathrm{mL} \mathrm{2,64} \mathrm{mL} \mathrm{dan} \mathrm{2,60} \mathrm{mL} \mathrm{masih} \mathrm{dalam} \mathrm{kondisi} \mathrm{normal.} \mathrm{Persentase} \mathrm{warna} \mathrm{semen} \mathrm{segar}$ kambing bangsa Peranakan Etawa (PE), Boer dan Saanen yang diperoleh pada bulan September, Oktober yaitu warna cream, pada bulan November diperoleh warna kuning, akan tetapi warna yang diperoleh masih dalam kondisi normal. Adapun konsistensi semen segar kambing bangsa Peranakan Etawa (PE), Boer dan Saanen yang diperoleh pada bulan September, Oktober, November yaitu konsistensi kental. Sedangkan pada variable pH semen segar kambing bangsa Peranakan Etawa (PE), Boer dan Saanen diperoleh perbandingan pada bulan September dan Oktober menunjukan tidak berbeda nyata, pada bulan September dan November menunjukan berbeda sangat nyata, dan pada bulan Oktober dan November menunjukan berbeda nyata, dimana rata-rata $\mathrm{pH}$ 6,63 6,65 dan 6,70 pH masih dalam kondisi normal. Adapun bau yang diperoleh yaitu bau khas yaitu bau anyir. Kesimpulannya adalah popolasi ternak kambing dari tiga bangsa yaitu bangsa peranakan etawa (PE), Boer dan Saanen yang ada di BIB Lembang, memiliki kualitas semen segar yang baik dan layak di gunakan untuk keperluan inseminasi buatan
\end{abstract}

Kata Kunci: Bangsa kambing, kualitas semen segar, periode koleksi semen

\begin{abstract}
MACROSCOPIC TEST OF FRESH SEMEN IN GOAT BREEDS OF ETTAWAH, BOER AND SAANEN AT LEMBANG ARTIFICIAL INSEMINATION CENTER. Research aim to evaluate the macroscopic quality of fresh semen in goat breeds of Ettawah, Boer and Saanen at Lembang Artificial Insemination Center. Direct observation was done to obtain primer data. Secondary data were found as additional data supporting primer data. Variables included in observation were involving semen volume, ejaculates, color, consistence,
\end{abstract}


$\mathrm{pH}$ and smell. Semen qualities of three breed groups collected on three sequent months were analyzed by $t$-test method. Results showed that semen qualities for ejaculates from three breed groups of Ettawah, Boer and Saanen collected on different months of September, October and November were not significantly different with the averages of $2.47 \mathrm{ml}, 2.64 \mathrm{ml}$ and $2.70 \mathrm{ml}$ respectively. Semen volume from three breed groups of Ettawah, Boer and Saanen collected on those different months were also not significantly different with the averages of significantly different with the averages of 2,30 2,64 and 2,60 mL, respectively. The percentages of color of fresh semen from Ettawah, Boer and Saanen collected on those different months were indicating cream of semen collected on September, October in Ettawah Grade, Boer and Saanen. Fresh semen of these breeds was indicating yellow color collected on November, but it was showing normal condition. Fresh semen of these breeds collected on those months were totally indicating thick consistency. However, $\mathrm{pH}$ of fresh semen in all three breeds of goat collected on September and October were significantly different with those collected on November. The $\mathrm{pH}$ of fresh semen in these breeds collected on September and October were not significantly different. Values of $\mathrm{pH}$ in these breeds collected on September, October and November were $6.63,6.65$ and 6.70 , respectively. These values were ranging in normal condition. The smell of fresh semen in these breeds collected on those series of months was indicating specific rancid smell.

Key words: Fresh semen quality, goat breed, semen collection period.

\section{PENDAHULUAN}

Kambing sering dikenal sebagai ternak ruminansia kecil merupakan ternak herbivora yang sangat populer di kalangan petani di Indonesia. Perkembangan jumlah populasi ternak kambing di Indonesia dari tahun 2000 sampai 2010 cenderung mengalami peningkatan yakni sebesar 7,4 $\%$ (BPS, 2010). Hal ini menjadi modal positif untuk mensukseskan program pemerintah mengenai swasembada daging, oleh karena itu perlu di lakukan upaya maksimal untuk lebih meningkatkan populasi ternak kambing.

Kualitas semen ditentukan oleh volume ejakulat, warna semen, $\mathrm{pH}$, konsistensi, persentase spermatozoa hidup, persentase abnormalitas spermatozoa, motilitas spermatozoa, dan konsentrasi spermatozoa (Delgadillo et al., 1991; Abecia et al., 2012). Menurut Pamungkas dan Batubara (2007), volume ejakulat semen domba atau kambing berkisar 0,8 1,2 mL, pH 5,9-7,3, konsentrasi 2000-3000 juta/mL, motilitas $60-80 \%$, spermatozoa normal $80-95 \%$. Akan tetapi menurut (Dewi et al., 2012; Giriboni et al., 2019) bahwa perbedaan umur ternak tidak menunjukkan perbedaan pada $\mathrm{pH}$ semen segar. Oleh karenanya, selain kualitas dan kuantitas semen segar dipengaruhi oleh bangsa, individu, pakan, metode penampungan semen, manajemen pemeliharaan dan faktor lingkungan (suhu dan musim). Menurut Leboeuf et al., 2004; Leboeuf et al. 2008; Hardijanto et al. (2008), kualitas semen yang baik harus melewati beberapa pemeriksaan antara lain pemeriksaan makroskopis dan pemeriksaan mikroskopis. Pemeriksaan makroskopis meliputi: volume, warna, bau, konsistensi, dan derajat keasaman atau $\mathrm{pH}$, Sedangkan untuk pemeriksaan mikroskopis meliputi: gerakan massa, gerakan individu, motilitas, konsentrasi spermatozoa serta prosentase hidup.

Berdasarkan latar belakang, perlu dilakukan pengamatan makroskopis semen segar kambing PE, boer dan saanen di Balai Insiminasi Buatan Lembang mengenai kualitas semen. Pengamatan ini bertujuan untuk mengetahui frekuensi penampungan ejakulasi semen dan menguji secara makroskopis semen segar kambing PE, boer dan saanen di Balai Insiminasi Buatan 
Lembang Bandung serta untuk mengetahui kondisi normal atau tidak semen segar kambing PE, Boer dan Saanen di Balai Insiminasi Buatan Lembang

\section{MATERI DAN METODE PENELITIAN}

\section{Lokasi dan Waktu Penelitian}

Penelitian ini dilaksanakan pada bulan November 2016 selama 2 minggu, bertempat di Balai Inseminasi Buatan (BIB) Lembang dengan suhu $19^{\circ} \mathrm{C}$.

\section{Materi penelitian}

Ternak yang di gunakan adalah populasi ternak kambing PE, boer dan Saanen yang berjumlah 17 ekor dan semen segar ternak kambing PE, boer dan saanen.

Peralatan

Adapun peralatan yang akandigunakan dalam penelitian ini adalah Vegina Buatan, Tabung Penampung Yang Berskala, Kandang Jepit, pH Meter, Pipet Ukur, pH Indicator Paper dan thermos air panas.

\section{Metode Penelitian}

Metode penelitian yang digunakan adalah metode pengamatan langsung dengan melakukan pemeriksaan pada semen kambing segar yang ditampung dengan menggunakan vagina buatan. Data yang akan digunakan adalah data primer dan sekunder. Data primer diperoleh langsung dari pengamatan makroskopis melalui pengamatan dengan menggunakan daftar tabel pengamatan serta wawancara yang berkaitan dengan reproduksi ternak kambing jantan dan observasi yang dilakukan di tempat pemeliharaan ternak kambing jantan dengan bantuan dari petugas Balai Inseminasi Buatan Lembang. Sedangkan data sekunder diperoleh dari informasi dan laporan dari Balai Inseminasi Buatan Lembang dan penelitian terdahulu yang berkaitan dengan penelitian ini, serta diperoleh dari instansi yang masih adakaitannya dengan penelitian ini, sehingga menunjang penelitian ini.
Variabel Penelitian dan Pengukurannya

Variabel penelitian terdiri pengukuran ejakulasi semen, volume semen, warna semen, konsistensi (derajat kekentalan) semen, $\mathrm{pH}$ (derajat keasaman) semen, bau semen

\section{Analisis Data}

Data dianalisis secara deskriptif dengan cara menghitung standar deviasi koefisien dan korelasi uji t. Variable yang diukur dalam penelitian ini yaitu kualitas semen secara makroskopik (Kafiar 2019) Data yang terkumpul dianalisis secara statistik deskriptif yaitu dengan tabulasi, rata-rata sampel, presentase, standar deviasi dan koefisien keragaman dengan persamaan sebagai berikut:

$$
\begin{aligned}
& (\mathrm{sd})=\sqrt{\frac{(\mathrm{X}-\overline{\mathrm{X}})^{2}}{\mathrm{n}-1}} \\
& \mathrm{XK}=\frac{\sum \mathrm{X}}{\mathrm{n}}
\end{aligned}
$$

Keterangan:

$\mathrm{X}=$ variabel yang diamati

$\overline{\mathrm{X}} \quad=$ Rata-rata variabel yang diamati

$\mathrm{n} \quad=$ Jumlah pengamatan variabel

$\mathrm{KK}=$ Koefisien Keragaman

Performan kualitas semen segar dari tiga bangsa kambing pejantan dalam tiga bulan di Balai Insemiansi Buatan (BIB) Lembang dilakukan melalui análisis varian melalui uji $\mathrm{t}$ atau $\mathrm{t}$ test (Byrkit, 1987). Uji t ini hanya digunakan pada variabel frekuensi penampungan ejakulasi semen, volumen semen dan $\mathrm{pH}$ semen.

Rumus uji t:

$$
t=\frac{\overline{\mathrm{x}}_{1}-\overline{\mathrm{x}}_{2}}{\sqrt{\frac{\mathrm{s}_{1}^{2}}{\mathrm{n}_{1}}+\frac{\mathrm{s}_{2}^{2}}{\mathrm{n}_{2}}}}
$$

Keterangan:

$\overline{\mathrm{X}}_{1}=$ Rata-rata nilai kelompok ke-1

$\overline{\mathrm{X}}_{2}=$ Rata-rata nilai kelompok ke-2

$\mathrm{S}_{1}^{2}=$ Varian kelompok ke-1

$S_{1}^{2}=$ Varian kelompok ke-2 
$\mathrm{n}_{1}=$ Banyak subjek kelompok ke-1

$\mathrm{n}_{2}=$ Banyak subjek kelompok ke-2

Pengamatan secara langsung, apakah memiliki bau khas yaitu anyir atau busuk yang disebabkan adanya gangguan atau infeksi pada bagian reproduksi jantan.

\section{HASIL DAN PEMBAHASAN}

Hasil pengamatan langsung dan pengambilan data kualitas semen segar kambing PE, Boer dan Saanen di BIB Lembang meliputi Ejakulat, Volume, Warna, Konsistensi, dan $\mathrm{pH}$.

\section{Ejakulat}

Hasil pemeriksaan ejakulat semen segar kambing PE, Boer, dan Saanen pada bulan September, Oktober dan November dapat dilihat pada Tabel 1.

Tabel 1. Rata-rata ejakulasi semen dan KK selama bulan September Oktober dan November

\begin{tabular}{lll}
\hline Bulan & $\begin{array}{l}\text { Rata-rata } \\
\text { Ejakulasi } \\
\text { Semen } \pm \text { SD } \\
(\mathrm{mL})\end{array}$ & $\begin{array}{l}\text { KK } \\
(\%)\end{array}$ \\
\hline September & $2,47 \pm 1,007$ & 40,769 \\
Oktober & $2,64 \pm 0,701$ & 26,553 \\
November & $2,70 \pm 0,848$ & 31,407 \\
\hline
\end{tabular}

Berdasarkan hasil penelitian yang disajikan dalam Tabel 1, terlihat bahwa rata-rata ejakulat semen segar kambing $\mathrm{PE}$, Boer, dan Saanen pada bulan November lebih tinggi yaitu 2,70 $\pm 0,848 \mathrm{~mL}$ dibandingkan dengan bulan September yang rata-rata ejakulasi $2,47 \pm 1,007 \mathrm{~mL}$ dan bulan Oktober yang rata-rata ejakulasi 2,60 $\pm 0,701 \mathrm{~mL}$. Jika dilihat dari koefesien keragaman ejakulasi semen segar kambing PE, Boer dan Saanen pada bulan September sampai November yaitu antara 26,553 sampai $40,769 \%$ berada pada keragaman yang tinggi. Jika koefisien keragaman > $15 \%$ maka dapat dilakukan seleksi (Ligda et al., 2000; Martin et al., 2004; Montalbano et al., 2016). Koefisien keragaman tinggi ini memberi arti bahwa banyak pejantan yang memiliki ejakulat semen dengan sebaran angka jauh dari angka rata-rata ejakulasi semen yang ada. Hasil tabulasi dan analisis data pada bulan September dan Oktober diperoleh nilai

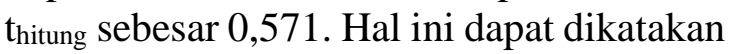
bahwa ejakulat semen kambing PE, Boer dan Saanen pada kedua bulan tersebut berbeda tidak nyata karena lebih kecil dari

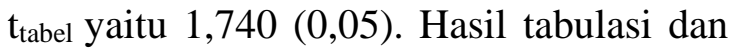
analisis data pada bulan September dan November diperoleh nilai $t_{\text {hitung }} 0,720 \mathrm{Hal}$ ini menunjukkan bahwa ejakulat semen kambing PE, Boer, dan Saanen pada kedua bulan tersebut berbeda tidak nyata $(\mathrm{p}<0,05)$. Adapun hasil tabulasi dan analisis data pada bulan Oktober dan November di peroleh nilai thitung 0,224 ini menunjukkan bahwa Ejakulat semen kambing PE, Boer dan Saanen pada ke dua bulan tersebut berbeda tidak nyata karena lebih kecil dari $t_{\text {tabel }}$ yaitu $1,740(0,05)$. Hal ini di sebabkan karena pejantan di Balai Inseminasi Buatan Lembang merupakan pejantan unggul yang sudah terseleksi dengan baik dan bersertifikat.

\section{Volume Semen}

Hasil pemeriksaan volume semen segar kambing PE, Boer, dan Saanen pada bulan September, Oktober dan November dapat dilihat pada Tabel 2.

Tabel 2. Rata-rata volume semen dan KK selama bulan September, Oktober dan November

\begin{tabular}{lll}
\hline Bulan & $\begin{array}{l}\text { Rata-rata } \\
\text { Volume Semen } \\
\pm \text { SD }(\mathrm{mL})\end{array}$ & $\begin{array}{l}\text { KK } \\
(\%)\end{array}$ \\
\hline September & $2,30 \pm 0,54$ & 23,47 \\
Oktober & $2,64 \pm 0,43$ & 16,28 \\
November & $2,60 \pm 0,53$ & 20,38
\end{tabular}

Berdasarkan hasil penelitian pada Tabel 2, secara makroskopik semen segar kambing PE, Boer dan Saanen pada ketiga bulan yaitu bulan September rata-rata volume 2,30 $\pm 0,54 \mathrm{~mL}$ dengan koefisien 
keragaman yaitu $23,47 \%$ selanjutnya pada bulan Oktober rata-rata volume 2,64 $\pm 0,43$ $\mathrm{mL}$ dengan koefisien keragaman 16,28\% dan pada bulan November rata-rata volume $2,60 \pm 0,53 \mathrm{~mL}$ dengan koefisien keragaman 20,38\%. Dilihat dari rataan volume ketiga bulan tersebut sedikit lebih dominan pada bulan Oktober. Jika dilihat dari koefisien keragaman volume semen segar kambing PE, Boer dan Saanen pada ketiga bulan tersebut berada pada keragaman yang tinggi, KK $>15 \%$. Koefisien keragaman volume semen segar kambing tiga bulan ini berada pada kisaran $16,28-23,47 \%$ yang menunjukan bahwa keragaman volume semen segar kambing ini lebih tinggi dari 15\%, sehingga dapat dikategorikan sangat tinggi (Qi et al., 2009; Wang et al. 2015; Zaja et al., 2018).

Hasil tabulasi dan analisi data nilai thitung yang di peroleh yaitu 2,031, pada bulan September dan Oktober ini dapat di katakan bahwa volume antara dua bulan tersebut berbeda nyata karena lebih besar dari $t_{\text {tabel }} 1,740(p>0,05)$. Perbedaan ini bisa terjadi karena dipengaruhi oleh bangsa, berat badan, makanan dan juga manajemen penampungan (Melita et al., 2013; Zarazaga et al., 2019). Hasil tabulasi dan analisis data pada bulan september dan november di peroleh nilai thitung yaitu 1,634 hal ini dapat dikatakan bahwa tidak berbeda nyata $(\mathrm{p}<0,05)$. Adapun hasil tabulasi dan analisis data pada bulan Oktober dan November nilai thitung yaitu 0,241 hal tersebut menjadikan volume dari kedua bulan tersebut tidak menunjukkan perbedaan tidak nyata $(\mathrm{p}<0,05)$. Hal ini di sebabkan karena pejantan yang ada di Balai Inseminasi Buatan merupakan pejantan unggul dan sudah memiliki sertifikat. Hal tersebut menjadikan volume semen yang diperoleh tidak menimbulkan perbedaan yang signifikan (Prayogo dan Maidaswar, 2013)

\section{Warna Semen}

Hasil pemeriksaan secara makroskopik bahwa warna semen segar kambing dari ketiga bangsa yaitu PE, Boer dan Saanen dapat dilihat pada Tabel 3.

Tabel 3. Rata-rata warna semen selama bulan September, Oktober dan November

\begin{tabular}{llll}
\hline \multirow{3}{*}{ Bulan } & \multicolumn{3}{c}{ Warna } \\
\cline { 2 - 4 } & $\begin{array}{l}\text { Cream } \\
(\%)\end{array}$ & $\begin{array}{l}\text { Kuning } \\
(\%)\end{array}$ & $\begin{array}{l}\text { Abnormal } \\
(\%)\end{array}$ \\
\hline September & 92,30 & 7,69 & 0 \\
Oktober & 66,67 & 33,33 & 0 \\
November & 17,31 & 76,92 & 5,77 \\
\hline
\end{tabular}

Berdasarkan hasil penelitian secara makroskopik semen segar kambing PE, Boer dan Saanen dari ketiga bulan tersebut, persentase warna semen segar dari ketiga bangsa kambing pada bulan September yaitu cream $92,30 \%$, kuning $7,69 \%$ dan abnormal $0 \%$. Adapun pada bulan Oktober persentase warna semen segar kambing dari ketiga bangsa yaitu cream $66,67 \%$, kuning $33,33 \%$ dan abnormal $0 \%$. Sedangkan pada bulan November persentase warna semen segar kambing dari ketiga bangsa tersebut yaitu cream $17,31 \%$, kuning $76,92 \%$ dan abnormal $5,77 \%$. Dilihat dari presentase warna cream lebih dominan pada bulan September dan Oktober sedangkan, pada bulan November yaitu lebih dominan warna kuning. Penelitian ini di dukung oleh (Toelihere, 1993) yang mengatakan bahwa semen kambing yang normal berwama cream kekuningan. Selanjutnya menurut (adhyatma et al., 2012) warna putih susu pada semen segar itu di katakana normal.

\section{Konsistensi (derajat kekentalan) Semen \\ Hasil pemeriksaan secara} makroskopik semen segar kambing PE, Boer dan Saanen dari bulan September, Oktober dan November dapat dilihat pada Tabel 4.

Hasil penelitian menunjukkan bahwa Konsistensi atau Derajat Kekentalan Kambing PE, Boer dan Saanen dari bulan September, Oktober dan November berada pada Konsistensi Kental, yaitu pada bulan September Konsistensi Kental 69,23, Selanjutnya pada bulan Oktober $60 \%$ dan 
pada bulan November 67,30\%. Sedangkan Konsistensi Sedang pada bulan September yaitu $30,76 \%$, adapun pada bulan Oktober

Tabel 4. Rata-rata konsistensi semen selama bulan September, Oktober dan November

\begin{tabular}{llll}
\hline \multirow{3}{*}{ Bulan } & \multicolumn{3}{c}{ Konsistensi } \\
\cline { 2 - 4 } & $\begin{array}{l}\text { Kental } \\
(\%)\end{array}$ & Sedang (\%) & $\begin{array}{l}\text { Encer } \\
(\%)\end{array}$ \\
\hline September & $69,23 \%$ & $30,76 \%$ & $0 \%$ \\
Oktober & $60 \%$ & $37,77 \%$ & $2,22 \%$ \\
November & $67,30 \%$ & $30,76 \%$ & $1,92 \%$ \\
\hline
\end{tabular}

$37,77 \%$ dan pada bulan November 30,76\%. Dan Konsistensi Encer pada bulan September yaitu 0\%, pada bulan Oktober 2,22\% dan pada bulan November 1,92\%.

Konsistensi, warna dan konsentrasi berkaitan satu sama lainnya. Bila warna semakin pudar, maka konsentrasi spermatozoa semakin menurun dan semen akan semakin encer begitu pula sebaliknya, bila warna semakin pekat maka konsentrasi spermatozoa semakin tinggi dan semen semakin kental (Toelihere, 1993). Konsistensi atau kekentalan merupakan salah satu sifat semen yang memiliki hubungan dengan konsentrasi spermatozoa di dalamnya. Semakin kental semen dapat diartikan semakin tinggi pula konsentrasi. Selanjutnya derajat kekentalan semen memiliki korelasi positif terhadap kandungan spermatozoa didalam semen sehingga apabila dalam pengamatan ditemukan semen yang terlalu encer maka dapat diduga bahwa semen tersebut memiliki konsentrasi spermatozoa yang rendah (Ariefin, 2013).

\section{pH (derajat keasaman) semen}

Hasil pemeriksaan $\mathrm{pH}$ semen segar kambing PE, Boer dan Saanen pada bulan September, Oktober dan November dapat dilihat pada Tabel 5 .

Berdasarkan hasil penelitian secara makroskopik semen segar kambing PE, Boer dan Saanen pada bulan September, Oktober dan November menunjukkan rata- rata volume semen segar kambing pada bulan September 6,63 \pm 0,075 dengan koefisien keragaman $1,131 \%$. Pada bulan

Tabel 5. Rata-rata $\mathrm{pH}$ dan KK selama bulan September, Oktober dan November

\begin{tabular}{lll}
\hline Bulan & $\begin{array}{l}\text { Rata-rata pH } \\
\text { Semen } \pm \text { SD }\end{array}$ & $\begin{array}{l}\text { KK } \\
(\%)\end{array}$ \\
\hline September & $6,63 \pm 0,075$ & 1,131 \\
Oktober & $6,65 \pm 0,059$ & 0,887 \\
November & $6,70 \pm 0,07$ & 1,045 \\
\hline
\end{tabular}

Oktober rata-rata volume semen segar kambing 6,65 $\pm 0,059$ dengan koefisien keragaman $0,887 \%$. Serta pada bulan November rata-rata volume semen segar kambing 6,70 $\pm 0,07$ dengan koefisien keragaman 1,045\%. Namun jika di bandingkan antara ketiga bulan tersebut sedikit lebih tinggi $\mathrm{pH}$ semen pada bulan November, namun rata-rata $\mathrm{pH}$ dari ketiga bulan tersebut tergolong dalam keadaan normal. Penelitian ini didukung oleh pendapat Hafez (2000), yang menyatakan bahwa $\mathrm{pH}$ semen kambing atau domba berkisar 5,9-7,3 adapun $\mathrm{pH}$ semen kambing PE 6,8. Menurut Souhoka (2009) bahwa, derajat keasaman semen segar mamalia berkisar antara 6-7,5.

Jika dilihat dari koefisien keragaman pada Tabel 5, ketiga bulan tersebut hampir seragam dan berada pada keragaman yang rendah $\mathrm{KK}<5 \%$. Koefisien keragaman $\mathrm{pH}$ semen tiga bulan ini berada pada kisaran $0,887-1,131 \%$ yang menunjukan bahwa keragaman $\mathrm{pH}$ semen ini kurang dari $5 \%$, sehingga dapat dikategorikan sangat rendah (Herdis et al., 2012).

Berdasarkan tabulasi dan analisis data di peroleh nilai thitung pada bulan September dan Oktober yaitu 0,862 yang berarti tidak berbeda nyata $\mathrm{p}<0,05$. Pada bulan September dan November nilai thitung yang di peroleh yaitu 2,822 yang artinya $\mathrm{pH}$ pada kedua bulan tersebut di katakan sangat berbeda nyata $p>0,01$. Adapun nilai thitung pada bulan Oktober dan November di peroleh 2,262 yang berarti $\mathrm{pH}$ dari kedua 
bulan tersebut berbeda nyata $p>0,05$. Perbedaan ini bisa terjadi karena dipengaruhi oleh bangsa, berat badan, makanan dan juga manajemen penampungan (Melita et al., 2014).

\section{Bau Semen}

Bau semen kambing atau aroma semen kambing mirip dengan bau semen pada umumnya, yaitu memiliki bau yang khas.Menurut pendapat Evan dan Maxwell (1987) semen kambing baunya anyir. Pendapat ini pun didukung (Hafez, 1987) serta Suyadi dan Isnaini (2004) yang menyatakan bahwa semen kambing memiliki bau yang khas yaitu bau anyir. Menurut (Kartasudjana, 2001) Semen kambing juga akan memiliki bau busuk. Bau busuk bisa terjadi apabila semen mengandung nanah yang disebabkan oleh adanya infeksi organ reproduksi jantan.

\section{KESIMPULAN}

Dari hasil penelitian bisa di simpulkan bahwa popolasi ternak kambing dari tiga bangsa yaitu bangsa peranakan etawa (PE), Boer dan Saanen yang ada di BIB Lembang, memiliki kualitas semen segar yang baik dan layak di gunakan untuk keperluan inseminasi buatan.

\section{DAFTAR PUSTAKA}

Abecia, J.A., F. Forcada, A. GonzalesBulnes. 2012. Hormonal control of reproduction in small ruminants. Animal Reproduction Science 130:173-179

Adhyatma, M., I. Nurul dan N. Nuryadi. 2012. Pengaruh bobot badan terhadap kualitas dan kuantitas semen sapi Simmental. Ternak Tropika 14(2): 53-62

Ariefin, A.P., R.T. Taswin dan M.S. Dadang. 2013. Kualitas semen segar sapi Simmental yang dikoleksi dengan interval yang berbeda di Balai Inseminasi Buatan Lembang. Jurnal Ilmiah Peternakan 1(3): 907-913
Delgadillo, J.A., B. Leboeuf, P. Chemineau. 1991. Decrease in the seasonality of sexual behavior and sperm production in bucks by exposure to short photoperiodic cycles. Theriogenology 36:755-770.

Dewi, S.A., Y.S. Ondho dan E. Kurnianto. 2012. Kualitas semen berdasarkan umur pada Sapi Jawa. Animal Agriculture Journal 1(2): 126-133

Giriboni, J., O. Gokdal, V. Eren, E. Yarali, J. Santiago-Moreno, R. Ungerfeld. 2019. Daily administration of a GnRH analogue enhances sperm quality in bucks during the nonbreeding season. Animal Reproduction Science. 200:43-50.

Hafez, E. S. E. 2000. Semen Evaluaation in Reproducation in Farm Animals.7 th Edition Lippncott Williams and Wiklins Maryland USA

Hardijanto, H., T. Sardjito, T. Hernawati, T. Susilowati dan T.W. Suprayogi. 2008. Penuntun Praktikum Fisiologi dan Teknologi Reproduksi (IB). Fakultas Kedokteran Hewan. Universitas Airlangga. Surabaya. P: 8-18.

Herdis. 2012. Pengaruh Waktu Penampungan Semen Terhadap Gerakan Massa Spermatozoa dan Tingka Laku Kopulasi Pejantan Domba Garut. J. Sains dan Teknologi Ind. Vol. 14(1). Hal: 38-43

Kartasudjana, R. 2001. Teknik Inseminasi Buatan Pada Ternak. Jakarta.

Kafiar, S.Y., S. Adiani, A. Lomboan, H.F.N. Lapian. 2019. Pengaruh fase mounting terhadap kualitas semen sapi limosin dan Simmental di Balai Inseminasi Buatan Lembang. Zootec 39(2): 417-426

Leboeuf, B, V. Furstoss, P. Guillouet, P. Boue. 2004. Production of artificial insemination doses from Alpine and Saanen bucks under various photoperiodic cycles. South African Journal of Animal Science 34:230 232. 
Leboeuf, B., J.A. Delgadillo, and E. Manfredi. 2008. Controlling reproduction in selection schemes of dairy goats. Production of Animal. 21:391-402

Ligda, C., G. Gabriilidis, T. Papadopoulos, A. Georgoudis. 2000. Estimation of genetic parameters for production traits of Chios sheep using a multitrait animal model. Livestock Science. 66:217-221.

Martin, G.B., J.T.B. Milton, R.H. Davison, G.E.B. Hunzicker, D.R. Lindsay, D. Blache. 2004. Natural methods for increasing reproductive efficiency in small ruminants. Animal Reproduction Science. 82 (83):231345.

Melita, D., Dasrul dan M. Adam. 2013. Pengaruh umur pejantan dan frekuensi ejakulasi terhadap kualitas spermatozoa sapi aceh. J. Medika veterinaria. Vol. 8(1): 15-19

Montalbano, M., R. Segreto, R. Di Gerlando, S. Mastrangelo, M.T. Sardina. 2016. Quantitative determination of casein genetic variants in goat milk: Application in Girgentana dairy goat breed. Food Chem.192:760-764.

Pamungkas, F. A. dan Batubara, 2007. Evaluasi Karakteristik Semen Beku Kambing Kosta.Lokakarya Nasional Domba dan Kambing.Stategipeningkatan Produksi Dan Mutu Bibit Domba dan Kambing.

Prayogo, K.U.E. dan T.R.T. Maidaswar. 2013. Hubungan ukuran lingkaran skrotum dengan volume semen, konsentrasi dan motilitas spermatozoa sapi limousine dan Simmental. Journal Ilmiah Peternakan 1(3): 1050-1056

Souhoka, D.F., M.J. Matatula, W.M. Mesang-Nalley dan M. Rizal. 2009. Laktosa mempertahankan daya hidup spermatozoa kambing peranakan etawa yang di preservasi dengan plasma semen domba priangan. Jurnal Veteriner 10(3): 135-142

Qi, Y., J. Luo, X.F. Han. 2009. Genetic diversity and relationships of 10 Chinese goat breeds in the Middle and Western China. Small Ruminant Research 82:88-93.

Suyadi, S.T. dan N. Isnaini. 2004. Uji Coba Produksi Semen Beku Kambing Boer. Laporan Penelitian Kerjasama Ditjen Peternakan Fakultas Peternakan Universitas Brawijaya Malang.

Toelihere, M.R. 1993. Inseminasi Buatan Pada Ternak. Angkasa. Bandung.

Wang, W., J. Luo, S. Sun. 2015. The effect of season on spermatozoa motility, plasma membrane and acrosome integrity in fresh and frozen-thawed semen from Xinong Saanen bucks. Reproduction of Domestic Animals 50:23-28.

Zaja, I.Z., S. Vince, S. Milinkovic-Tur. 2018. Exogenous melatonin influences distribution of French Alpine buck spermatozoa in morphometrically distinct subpopulatons during the nonbreeding season. Animal Reproduction Science 192:154-163.

Zarazaga, L.A., M.C. Gatica, H. Hernandez, P. Chemineau, J.A. Delgadillo, J.L. Guzman. 2019. Photoperiod-treated bucks are equal to melatonin-treated bucks for inducing reproductive behavior and physiological functions via the "male effect" in Mediterranean goats. Animal Reproduction Science. 202:58-64 